\title{
EFEITO DA ADUBAÇÃO FOLIAR NA PRODUÇÃO DE MUDAS DE ABÓBORA MENINA BRASILEIRA
}

Luis Eduardo Vieira Pinto ${ }^{1}$, Thadeu Henrique Novais Spósito ${ }^{2}$, Angela Madalena Marchizelli Godinho', Fernando Bernardo Martins ${ }^{3}$

1Universidade do Oeste Paulista - UNOESTE, Programa de Pós-Graduação em Agronomia, Doutorado, Presidente Prudente,SP. ${ }^{2}$ Universidade Estadual Paulista - UNESP, Programa de Pós-Graduação em Agronomia, Ilha Solteira,SP. ${ }^{3}$ Universidade do Oeste Paulista - UNOESTE, Programa de Pós-Graduação em Agronomia, Presidente Prudente,SP E-mail: levp@unoeste.br

\section{RESUMO}

A cultura da abóbora menina brasileira, é uma cultura considerada de simples manejo e relativamente de baixo custo, possuindo uma boa adaptação ao clima brasileiro. Visando uma alternativa mais viável para os produtores que procuram maior rendimento da cultura, foi desenvolvido um experimento com o objetivo de avaliar doses ideais de fertilizantes foliares a base de N-P-K. Utilizou-se o delineamento experimental inteiramente casualizado, contendo 4 tratamentos doses de fertilizante foliar sendo T0 (testemunha sem uso de fertilizante), T1 (2,5ml, dosagem indicada pelo fabricante do fertilizante), T2 (5 ml para 1 litro de água), e T3 (10 ml para 1 litro de água), com 20 repetições e 1 planta por unidade experimental. Todos os dados foram submetidos à análise de variância (ANOVA, $p<0,05$ ) e ao teste de comparação de médias Tukey $(p<0,05)$, segundo Silva (2011). A dosagem de 5 e $10 \mathrm{ml}$ promoveram o melhor desenvolvimento das mudas de abóbora.

Palavras-chave: Agronegócio. Fertilizante. Hortaliças. Cucurbita moschata. Substrato.

\section{EFFECT OF FERTILIZER ON LEAF PRODUCTION PUMPKIN BRAZILIAN GIRL DUMB}

\begin{abstract}
The culture of the Brazilian girl pumpkin, is considered culture of simple handling and relatively low cost, having a good adaptation to the Brazilian climate. For a more viable alternative for producers seeking greater crop yield, an experiment was conducted in order to evaluate optimal doses of foliar fertilizers N-P-K base. We used a completely randomized design treatments containing 4 doses of foliar fertilizer and TO (control without fertilizer use), T1 $(2.5 \mathrm{ml}$, dosage indicated by the fertilizer manufacturer), T2 (5 ml to 1 liter of water) and T3 (10 ml for 1 liter of water), with 20 repetitions, and 1 plant per experimental unit. All data were subjected to analysis of variance (ANOVA, $p<0.05$ ) and the mean comparison Tukey test $(p<0.05)$, according to Silva (2011). The dosage of 5 and $10 \mathrm{ml}$ promoted the best development of pumpkin seedlings.

Keywords: Agribusiness. Fertilizer. Vegetables. Cucurbita moschata. Substrate.
\end{abstract}




\section{INTRODUÇÃO}

As hortaliças possuem um alto valor nutritivo, principalmente pelo conteúdo de sais minerais e vitaminas, portanto, é recomendado o seu consumo no cardápio como forma de suprir as necessidades diárias desses elementos. Além disso, o consumo de hortaliças facilita a digestão dos alimentos (MAKISHIMA, 1992).

A produção de hortaliças requer adequado fornecimento de nutrientes, desde o estádio de plântula até a colheita. O desequilíbrio nutricional, seja por carência ou excesso de nutrientes, é fator estressante para a planta, que influenciará, diretamente, na produção e na qualidade final do produto.

A abóbora (Cucurbita moschata) é de cultivo anual, com crescimento "indeterminado" onde as ramas alongam-se até seis metros. Na mesma planta encontram-se flores femininas (que originam os frutos) e masculinas (que fornecem o pólen), sendo que o fruto só se desenvolve a partir de flores femininas fecundadas através de polinização. Essa polinização garante boa produtividade e frutos sem deformações. As abóboras são cultivadas em todo território brasileiro e desempenham um importante papel para a alimentação humana. Estão presentes em nossa dieta desde a formação das primeiras civilizações do mundo até os dias atuais (AQUINO, 2010).

A abóbora menina brasileira é uma planta herbácea, anual, bastante pubescente, de caule robusto e comprido (até cerca de $10 \mathrm{~m}$ ) prostrado a trepador, provido de gavinhas e de folhas grandes (até mais de $25 \times 30 \mathrm{~cm}$ ), de contorno mais ou menos arredondado a ovalado cordiforme e com três a cinco lobos, as folhas verdes a verde-acinzentadas apresentam manchadas de branco, distribuídas no seu limbo, o prateamento (FILGUEIRA, 2008). Tem como expressão do sexo a monoicia, assim como as demais espécies do gênero, com flores grandes, vistosas e alaranjadas ocorrendo isoladas em axilas foliares. A flor masculina une-se à planta por meio de um pedúnculo fino e possui três anteras mais ou menos unidas, que produzem uma quantidade abundante de pólen pegajoso e pesado. A flor feminina tem pedúnculo curto, os estilos estão fundidos em quase toda a extensão e são livres no ápice. Os estigmas são grandes carnudos e apresentam dois lóbulos, ovário ínfero, bem aparente, dividido internamente em três ou cinco carpelos (PUIATTI e SILVA, 2005).

Os pedúnculos (forma pentagonal, duro e lenhoso) tornam-se bastante sulcados, alargando-se junto dos frutos, possibilitando o desenvolvimento de frutos com formatos peculiares, alongados, popularmente denominados como "de pescoço", com polpa amarela a alaranjada e sementes brancas. O fruto é uma baga indeiscente, com polpa que pode variar da coloração branca, amarela a alaranjada escura, além de ter também uma grande variabilidade para coloração da casca ou epicarpo do fruto e uma média de 100 a 300 sementes (FILGUEIRA, 2008).

A menina brasileira adapta-se a vários tipos de solos, mas preferem os de textura média, bem drenados, leves e de boa fertilidade. $\mathrm{O}$ pH variável entre 5,8 e 6,8. Plantas de clima quente, preferindo temperaturas de 20 a $27^{\circ} \mathrm{C}$ (LANA et al., 2008).

O sucesso do cultivo de hortaliças depende em grande parte da utilização de mudas de alta qualidade, o que torna o cultivo de hortaliças mais competitivo, com o aumento de produtividade e diminuição dos riscos de produção (MINAMI, 1995). A produção de mudas de hortaliças sob cultivo protegido tem apresentado um crescimento expressivo, em decorrência das vantagens em relação ao sistema tradicional.

A base da horticultura moderna é a produção de mudas de alta qualidade e uma muda bem formada dará origem a uma planta com alto potencial produtivo. Para produtores de mudas, ocorre a tendência de se comercializarem mudas mais novas, para reduzir o tempo destas no viveiro de produção. Já, os produtores que irão cultivar estas mudas, preferem-nas mais desenvolvidas. Provavelmente, essa preferência está relacionada com a facilidade de transplante, 
pois estas apresentam um sistema radicular compacto, estruturado com um torrão que não se quebra no momento da retirada das bandejas (SEABRA JÚNIOR et al., 2004).

Para viabilizar o aumento da produtividade de hortaliças como a abóbora menina brasileira faz-se necessária a utilização de mudas de boa qualidade associada ao manejo adequado da cultura. Entretanto, a obtenção de mudas de qualidade ainda representa um desafio, pois depende do uso de substratos com boas condições sanitárias e com propriedades físico-químicas que favoreçam o crescimento e o desenvolvimento inicial das plantas.

A adubação foliar é uma prática extremamente importante para a exploração racional das culturas agrícolas, sendo fundamental para a obtenção de bons rendimentos (PÔRTO et e al., 2012). A adubação adequada é bem equilibrada, traz ao produtor não só ganhos em produtividade, mas também a melhoria da qualidade da produção, estado fitossanitário das plantas, entre outros benefícios (TAVARES et e al., 1995). Para a aplicação de fertilizante, deve-se considerar a dinâmica de absorção de nutriente pela planta, evitando-se a carência ou a disponibilidade excessiva no solo, o que geralmente causa desequilíbrio na absorção de outros elementos (NATALE, 2003). Todavia, de acordo com a produtividade que se deseja alcançar e o estado nutricional da cultura, pode-se fazer ajustes nos valores recomendados para a fertilização da cultura. Desta forma alguns fatores devem ser levados em consideração, como cultivar técnicas de manejo, fonte de nutriente e considerações climáticas (PÔRTO et e al., 2012).

O nitrogênio é um nutriente que influencia os processos envolvidos no crescimento e desenvolvimento das plantas, alterando a relação fonte-dreno e, consequentemente, a distribuição de assimilados entre órgãos vegetativos e reprodutivos. Em cucurbitáceas, o aumento da dose de $\mathrm{N}$, até determinado limite, proporciona incremento na área foliar da planta; portanto, exerce efeito da fotoassimilados e, consequentemente, na produção de frutos (QUEIROGA et al., 2007).

O fósforo é essencial para a boa formação de sementes e frutos e participa de um grande número de compostos das plantas essenciais em diversos processos metabólicos, além de estimular o crescimento radicular. Sua deficiência provoca atraso no florescimento e redução no número de sementes e frutos. A fitina é a principal forma de armazenamento de fósforo na semente e possui uma função durante a germinação da semente (MARSCHNER, 1995).

Segundo Pittela (2006), o potássio é exigido pelas plantas em grande quantidade e sua função está relacionada especialmente com as enzimas que participam em quase todas as reações da planta. No período da frutificação, auxilia no enchimento e no crescimento das sementes. Por outro lado, a sua deficiência é caracterizada pelo crescimento lento, plantas com raízes pouco desenvolvidas, caules fracos e muito flexíveis, plantas mais suscetíveis a ataques de doenças e à formação de sementes e frutos pouco desenvolvidos.

No Brasil, observa-se a necessidade de maiores pesquisas sobre doses de fertilizantes a serem utilizadas, nas diferentes cultivares, regiões e épocas de plantio (BASTOS et al., 2008). Além disto, na ansiedade de obter maior produtividade, o olericultor aplica em excesso, elementos minerais, resultando muitas vezes em distúrbios nutricionais nas plantas e, consequentemente, acarretam no aumento do custo de produtividade (RESENDE et al., 2005).

O trabalho teve por objetivo propor o uso de adubação foliar (N-P-K) para a produção de mudas de abóbora menina brasileira, bem como identificar a dosagem que irá promover o melhor desenvolvimento das mudas.

\section{METODOLOGIA}

O experimento foi conduzido na Fatec (Faculdade de Tecnologia de Presidente Prudente), sua implantação foi realizada no dia 25/05/2015. Utilizou-se o delineamento experimental inteiramente casualizado, contendo 4 tratamentos doses de fertilizante foliar (Nitrogênio 8\%, Fósforo 6\%, Potássio 6\%), produto comercial da marca FERTILIZANTE VIDA VERDE, com 20 
repetições e 1 planta por unidade experimental. Os tratamentos utilizados foram: T0 (Testemunha); T1 (2,5 ml de produto comercial por litro de água); T2 (5 ml de produto comercial por litro de água) e T3 (10 ml de produto comercial por litro de água). Para a execução do ensaio, utilizou-se semente tratada de abóbora Cucurbita Moschata Duchesne do cultivar "Menina brasileira" da marca TOPSEED com 99,9\% de pureza e $85 \%$ de germinação. As sementes foram semeadas a $1,5 \mathrm{~cm}$ de profundidade em copos de isopor contendo substrato com capacidade de $100 \mathrm{ml}$. Os copos foram dispostos sobre uma grade metálica com elevação de aproximadamente 1 $\mathrm{m}$ do solo, que ficavam no interior da estufa da Fatec. As mudas eram irrigadas diariamente em dois períodos distintos do dia (09:00 e as 15:00 horas)

Quinze dias após a semeadura foi realizada a primeira aplicação do fertilizante foliar nas mudas, essas aplicações foram repetidas a cada 5 dias $\left(20^{\circ}, 25^{\circ}\right.$ e $30 \circ$ dias após a semeadura). No 34 - dia as mudas foram coletas e levadas para a realização das análises de comprimento da raiz, comprimento da parte aérea, massa seca da raiz e massa seca da parte aérea. 0 comprimento da raiz e parte aérea foi realizado utilizando de uma fita métrica aprovada e homologada pelo Inmetro (Instituto Nacional de Metrologia, Qualidade e Tecnologia). Para a determinação da massa seca da raiz e parte aérea foi utilizado uma estufa de circulação de ar quente no qual as mudas ficaram por um período de 72 horas a uma temperatura na faixa de 65-75으.

Todos os dados foram submetidos à análise de variância (ANOVA, $p<0,05$ ) e ao teste de comparação de médias Tukey $(p<0,05)$, segundo Silva (2011).

\section{RESULTADOS}

Tabela 01. Resultados de análises estatísticas das variáveis analisadas "Comprimento da Parte Aérea (CPA) e Massa Seca da Parte Aérea (MSPA)" em relação aos tratamentos utilizados no experimento.

\begin{tabular}{ccc}
\hline TRATAMENTOS & CPA $(\mathrm{cm})$ & MSPA $(\mathrm{g})$ \\
\hline Testemunha & $12,05 \mathrm{c}$ & $0,45 \mathrm{c}$ \\
$2,5 \mathrm{ml}$ & $17,98 \mathrm{~b}$ & $0,68 \mathrm{~b}$ \\
$5 \mathrm{ml}$ & $21,50 \mathrm{a}$ & $0,82 \mathrm{a}$ \\
$10 \mathrm{ml}$ & $22,90 \mathrm{a}$ & $0,93 \mathrm{a}$ \\
\hline $\mathrm{MG}$ & 18,61 & 0,72 \\
\hline CV (\%) & $15,92 * *$ & $21,69 * *$ \\
\hline
\end{tabular}

Médias seguidas por letras iguais na coluna não diferem entre si pelo teste de Tukey a 5\%.

Tabela 02. Resultados de análises estatísticas das variáveis analisadas "Comprimento da Raiz (CR) e Massa Seca da Raiz (MSR)" em relação aos tratamentos utilizados no experimento.

\begin{tabular}{ccc}
\hline TRATAMENTOS & CR $(\mathrm{cm})$ & MSR $(\mathrm{g})$ \\
\hline Testemunha & $19,83 \mathrm{a}$ & 0,2 \\
$2,5 \mathrm{ml}$ & $23,33 \mathrm{a}$ & 0,2 \\
$5 \mathrm{ml}$ & $20,00 \mathrm{a}$ & 0,2 \\
$10 \mathrm{ml}$ & $24,43 \mathrm{a}$ & 0,21 \\
\hline $\mathrm{MG}$ & 21,89 & 0,2 \\
\hline $\mathrm{CV}(\%)$ & $28,39 * *$ & $23,17^{\mathrm{ns}}$ \\
\hline
\end{tabular}

Médias seguidas por letras iguais na coluna não diferem entre si pelo teste de Tukey a $5 \%$.

\section{DISCUSSÃO}

No sistema produtivo das hortaliças uma das partes mais importantes, é a produção das mudas, pois consequentemente, influencia na produção final das plantas. Os produtores têm buscado novas técnicas para a produção de mudas, com qual essa coloca-se apenas uma semente por célula e com o transplante, garante uma população uniforme e sem falhas. Ao contrário, na 
semeadura direta usualmente são colocadas duas ou três sementes por cova, para se tentar obter a mesma população de plantas, a utilização de mudas permite melhor aproveitamento das sementes, facilita a realização dos tratos culturais iniciais, proporciona maior homogeneidade das plantas, diminuindo a possibilidade de falhas na área e garantindo a população desejada.

Através dos resultados expressos na Tabela 01 observa-se que o desenvolvimento inicial das mudas de abóbora menina brasileira em relação ao tamanho das plantas e na massa seca foram influenciados positivamente quando aplicado o fertilizante foliar a partir da dosagem correta até a dosagem máxima testada no experimento.

Dentro das diversas doses utilizadas no experimento, aquelas que mais se destacaram para o desenvolvimento das mudas da abobora menina brasileira foram as doses de 5 e $10 \mathrm{ml}$, porém a dose de $5 \mathrm{ml}$ torna-se economicamente mais viável ao produtor, pois os resultados os resultados obtidos no experimento nessas duas doses foram estatisticamente iguais o que gera uma economia na aplicação do fertilizante.

\section{CONCLUSÃO}

O uso de fertilizante foliar foi viável para a produção de mudas de abóbora menina brasileira.

A dosagem de $5 \mathrm{ml}$ torna-se eficaz pelo tanto pelo quesito de desenvolvimento da muda, quanto pelo fator econômico.

\section{REFERENCIAS}

AQUINO, R.S.L. História das sociedades americanas. Rio de Janeiro: Record, 2010. p. 45-46, 54-67, 80.

BASTOS, E. A.; CARDOSO, M.J.; MELO, F.B.; RIBEIRO, V.G; Andrade Junior, A.S. Doses e formas de parcelamento de nitrogênio para a produção de milho sob plantio direto. Revista Ciência Agronômica, v 39, n.2, p 275-280, 2008.

FILGUEIRA, F.A.R. (2008) Novo manual de olericultura: agrotecnologia moderna na produção e comercialização de hortaliças. 3 ed. Viçosa: UFV, 421p.

LANA, M.; DOS SANTOS, F.F.; LUENGO, R.F.A.; TAVARES, S.S.; DE MELO, M.F,; MATOS, M,J,L,F. Embrapa hortaliças. 2008. Disponível em: <cnph.embrapa.br/laborato/pos_colheita/dicas/abobora_madura.htm> Acesso em 30/10/2015. MAKISHIMA, N. Cultivo de hortaliças, 2.ed. Brasília: EMBRAPA - CNPH, 1992. 26 p. (EMBRAPA. CNPH. Instruções Técnicas, 6).

MARSCHNER, H. Mineral Nutrition of higher plants. 2. Ed. London: A.P, 1995. 889 p.

MINAMI, K. (Ed.) Produção de mudas de alta qualidade em horticultura. São Paulo: T.A Queiroz, $199512 \mathrm{p}$.

NATALE, W., Calagem, adubação e nutrição da goiabeira. In ROZANE, D.E.; COUTO, F.A.A.; E.J.A. (EDS). Cultura da goiabeira: Tecnologia e mercado. VIÇOSA: UFV/EJA, 2003. p. 303 -331.

PITELLA LC. 2006. Fertilização In: Bonsai Cube Morro Velho, setembro 2003. Disponível em: htpp//WWW.bonsaimorrovelho.com.br/bcmv MT fertilização.html. Acesso em 10/10/2015.

PÔRTO, M. L. A.; PUIATTI, M.; FONTES, P. C. R.; CECON, P. R.; ALVES, J. C.; ARRUDA, J. A. (2012). Produtividade e acúmulo de nitrato nos frutos de abobrinha em função da adubação nitrogenada.Bragantia, 71(2), 190-195. https://doi.org/10.1590/S0006-87052012005000020

PUIATTI, M., SILVA, D.J.H. (2005) Abóboras e morangas. In: Fontes, P.C.R. (ed.). 
Olericultura: teoria e prática. Viçosa: DFT - Setor de Olericultura/UFV, p.279-297.

QUEIROGA RCF; PUIATTI M; FONTES PCR; CECON PR FINGER FL. 2007. Influência de doses de nitrogênio na produtividade e qualidade do melãoCantalupensis sob ambiente protegido. Horticultura Brasileira 25: 550-556. https://doi.org/10.1590/S0102-05362007000400011

RESENDE, G.M.; ALVARENGA, M.A.R.; YURI, J.E.; MOTA, J. H.; SOUZA, R.J.; RODRIGUES JÙNIOR, J.C. Produtividade e qualidade pós-colheita da alfaceamericana em função de doses de nitrogênio e molibdênio. Horticultura Brasileira, Brasília, v.23, n.4, p.976-981, 2005. https://doi.org/10.1590/S0102-05362005000400023

SEABRA JÚNIOR, S.; GADUM, J.; CARDOSO, I.I. Produção de pepino em função da idade das mudas produzidas em recipientes com diferentes volumes 34 de substrato. Horticultura Brasileira, Brasília, v,22, n.3, p.610-613, jul./set .2004.

SILVA, F. de A.S. Assistat software. Assistência Estatística. Versão 7.6.beta (2011). Disponível em http://www.assistat.com/indexp.html. 